\title{
Durability evaluation of circulating fluidized bed fly ash-based geopolymer
}

\author{
Li Dongsheng ${ }^{1}$ and Zhou Xinxing, ${ }^{2 *}$ \\ ${ }^{1}$ Shanxi Road \& Bridge Construction Group Co., Ltd, Taiyuan Shanix, 030006, China \\ ${ }^{2}$ Key Laboratory of Highway Construction and Maintenance Technology in Loess Region of Ministry of Transport, Shanxi \\ Transportation Technology Research \& Development Co., Ltd, Taiyuan 030032, China
}

\begin{abstract}
To make full use of the circulating fluidized bed fly (CFB-FA), rich-water carbide slag was used as alkali-activator to promote the hydration of CFB-FA and prepare circulating fluidized bed fly-based geopolymer (CFB-FAG). The fundamental properties, mechanical properties, and acid alkali-resistance of CFB-FAG were investigated. The optimum content of CFB-FA is $25 \%$. it indicates that CFB-FA can prepare the excellent properties of geopolymer without high-temperature heat treatment. The alkali resistance of CFB-FAG is better than that of acid resistance. Furthermore, the fatigue lifetime of CFB-FAG decreases by $20 \%$ after acid treatment. The achievement can help us make full use of the solid waste and achieve the goal of peak carbon dioxide emissions and carbon neutral.
\end{abstract}

\section{Introduction}

The annual output of fly ash from power plants reached up to 600 million tons at 2020. China is the largest emitter of fly ash, but the utilization rate of fly ash has not been high so far. The comprehensive utilization of fly ash is imminent [1]. Regarding the discharge of industrial solid waste, the United States is the first country to put forward environmental protection. The U.S. government enacted the "Super Fund Act", which stipulates:-Any enterprise that produces industrial waste must properly dispose of it on its own and cannot dump it at will $[2,3]$.

Circulating fluidized bed fly ash (CFB-FA), acted as a unusual fly ash, usually did not have the reactivity at room temperature, which need high-temperature calcination to promote the reactivity and add alkaliactivator or cement to reduce the curing temperature [4]. CFB-FA is a solid particle formed by the process of decomposition, sintering, melting and cooling of the coal. It mainly consists of oxides such as $\mathrm{SiO}_{2}, \mathrm{Al}_{2} \mathrm{O}_{3}, \mathrm{FeO}$, $\mathrm{Fe}_{2} \mathrm{O}_{3}$, and also contains a small amount of rare metals such as molybdenum, silver, and chromium [5]. CFB-FA has the advantages of fine particles, light weight, large specific surface area, and strong water absorption [6]. At this stage, CFB-FA is mainly used in construction, building materials, transportation, and soil improvement. The application of CFB-FA accounts for $80 \%$ in construction, building materials, and transportation. The application of CFB-FA accounts for $15 \%$ in agriculture. However, they are all low value-added products which are not sufficient to its potential value. Make full use of the characteristics of CFB-FA to develop the high valueadded fly ash utilization technology. Vigorously developing high value-added products of CFB-FA is the main direction of research on the utilization of fly ash resources in the future. At this stage, only a small amount of CFB-FA is used in high-value utilization fields such as industry and environmental protection, such as the preparation of white carbon black, zeolite, and the recovery of rare metals [7]. In addition, there are high value-added utilization technologies of CFB-FA such as the treatments of wastewater, waste oil, and exhaust gas [8]. The high value-added utilization technology of CFB-FA should be paid attention to. CFBFA was used to prepare the geopolymer, which will become a hot topic[9]. However, there exists a serious problem that CFB-FA do not have the reactivity at room temperature and irregular particle morphology.

In this study, we use the CFB-FA, cement, rich-water carbide slag, sodium hydroxide to prepare the circulating fluidized bed fly-based geopolymer (CFB-FAG). The fundamental properties, mechanical properties, and acid alkali-resistance of CFB-FAG were investigated using $\mathrm{X}$-ray diffractometer, scanning electron microscope, and universal material testing machine.

\section{Materials and methods}

\subsection{Raw materials}

CFB-FA and rich-water carbide slag came from Shanxi Sanwei Huabang Group Co. Ltd. CFB-FA was the solid waste from CFB burning. Rich-water carbide slag was the solid waste from polyvinyl chloride preparation. Sodium hydroxide, potassium hydroxide, hydrochloric acid, nitric acid, and sulfuric acid (analytically pure)

\footnotetext{
*Corresponding author: zxx09432338@whut.edu.cn
} 
were bought from Shanxi Feida Technology and Trade Co. Ltd and its concentration was $10 \mathrm{~mol} / \mathrm{L}$. 42.5 P.O cement was bought from Linfen Shanshui Cement Co. Ltd and its fundamental properties showed in Table 1.

Table 1. The fundamental properties of cement.

\begin{tabular}{ccccc}
\hline Terms & $\begin{array}{c}\text { Specific } \\
\text { area } \\
(\mathrm{m} 2 / \mathrm{kg})\end{array}$ & $\begin{array}{c}\mathrm{Gel} \\
\text { time } \\
(\mathrm{min})\end{array}$ & $\begin{array}{c}\mathrm{SO}_{3} \\
\text { content } \\
(\%)\end{array}$ & $\begin{array}{c}\text { Compressive } \\
\text { strength (MPa) }\end{array}$ \\
\hline Properties & 352 & 52 & 2.85 & 43.2 \\
Standards & $>300$ & $45-600$ & $<3.50$ & $>42.5$ \\
\hline
\end{tabular}

\subsection{The preparation of CFB-FAG}

The CFB-FA was added into cement and stirred evenly at first. Then, rich-water carbide slag and sodium hydroxide were added into this system and stirred 30 min with $150 \mathrm{rpm}$ to get the CFB-FAG. The basic composition of CFB-FAG showed in Table 2.

Table 2. The basic composition of CFB-FAG (g).

\begin{tabular}{ccccc}
\hline Sample & Cement & $\begin{array}{c}\text { CFB- } \\
\text { FA }\end{array}$ & $\begin{array}{c}\text { Rich-water } \\
\text { carbide slag }\end{array}$ & $\begin{array}{c}\text { Sodium } \\
\text { hydroxide } \\
\text { solution }\end{array}$ \\
\hline S1 & 40 & 10 & 5 & 45 \\
S2 & 35 & 15 & 5 & 45 \\
S3 & 30 & 20 & 5 & 45 \\
S4 & 25 & 25 & 5 & 45 \\
S5 & 20 & 30 & 5 & 45 \\
\hline
\end{tabular}

\subsection{The phase composition test of raw materials}

The phase compositions of CFB-FA and rich-water carbide slag were measured by X-ray diffraction (XRD, Olympus, Terra 508). The angle ranged from $5^{\circ}$ to $55^{\circ}$. The chemical compositions of CFB-FA and rich-water carbide slag can be see the reference [10], which were measured by using X-ray fluorescence (XRF) analysis.

\subsection{The mechanical properties test of CFB-FAG}

The mechanical properties of CFB-FAG were measured by universal material testing machine (UTM) according to GB/T 17671-1999. The compressive strength of CFBFAG samples selected the samples after curing 7 days. The fatigue lifetime of CFB-FAG was tested according to JTG E20-2011.

\subsection{The durability test of CFB-FAG}

The durability of CFB-FAG was evaluated by acid and alkali referenced to JTG E30-2015. The acid solution selected $6 \mathrm{~mol} / \mathrm{L} \mathrm{HCl}, \mathrm{HNO}_{3}$, and $\mathrm{H}_{2} \mathrm{SO}_{4}$. The alkali solution selected $\mathrm{NaOH}(0.5 \mathrm{~mol} / \mathrm{L}, 2 \mathrm{~mol} / \mathrm{L}$, and 6 $\mathrm{mol} / \mathrm{L})$ and $\mathrm{KOH}(0.5 \mathrm{~mol} / \mathrm{L})$. The morphology was measured by scanning electron microscope (SEM, JSM5610LV). Owing to existing the $\mathrm{Fe}_{2} \mathrm{O}_{3}$ in the geopolymers, the geopolymer is magnetic, so, there need to expand the height between sample and probe. Fourier infrared spectrometer (FT-IR, Nicolet, IS5) was used to measure the functional groups of CFB-FAG after acid or alkari treatment. The wavenumbers ranged from $400 \mathrm{~cm}$. ${ }_{1}$ to $4000 \mathrm{~cm}^{-1}$. The scanning time is 32 and the scanning step is $4 \mathrm{~cm}^{-1}$.

\section{Results and discussions}

\subsection{The phase composition of CFB-FAG}

As shown in Figure 1, the XRD results of CFB-FA show that the main components of CFB-FA are amorphous silica-alumina vitreous. And there are lots of rags. It indicates that CFB-FA exists in an amorphous structure. The main components of CFB-FAG are $\mathrm{NaAlSiO}_{3}$, $\mathrm{CaSiO}_{3} \cdot \mathrm{H}_{2} \mathrm{O}$, and amorphous $\mathrm{SiO}_{2}$. Also, with the increase of CFB-FA content, the main phase compositions of CFB-FAG changed slightly. The results show that CFB-FA could not change significantly the structure of CFB-FAG with the increase of CFB-FA content.

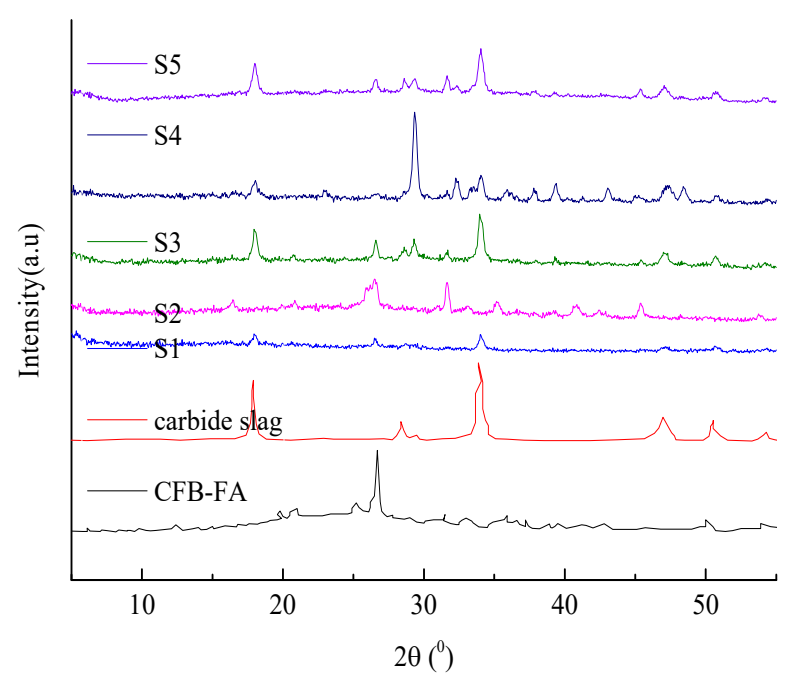

Figure 1. The XRD of CFB-FA.

\subsection{The mechanical properties of CFB-FAG}

As shown in Figure 2, the compressive strength curves of CFB-FAG show that the compressive strength of CFB-FAG increase as increased with CFB-FA content at first. Then, the compressive strength of CFB-FAG decrease as increased with CFB-FA content when the CFB-FA content is above $25 \%$. The compressive strenght of all CFB-FAG are above $42.5 \mathrm{MPa}$, which shows that the compressive strength of geopolymer is bigger than that of cement and CFB-FA will increase the mechanical properties of cement-based geopolymer. It indicates that CFB-FA can affect significantly the mechanical properties of CFB-FAG and the optimum content of CFB-FA is $25 \%$. 


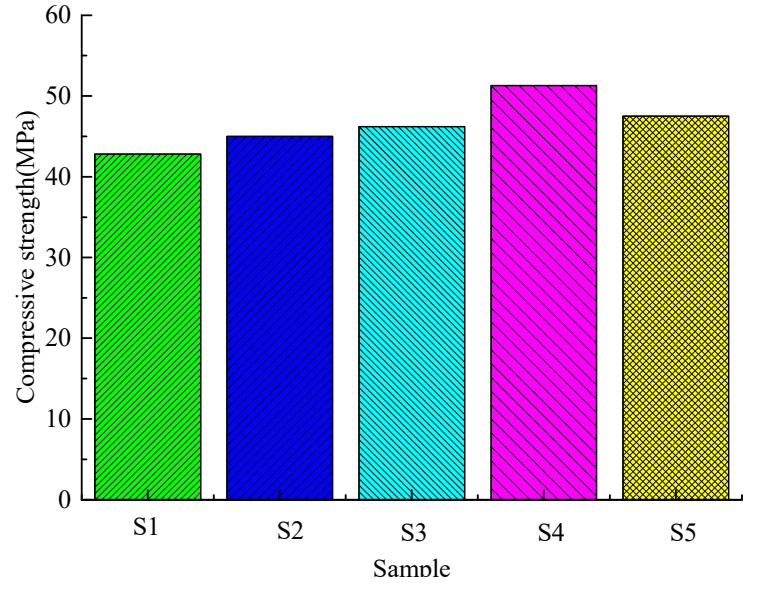

Figure 2. The compressive strength of CFB-FAG.

\subsection{The fatigue lifetime of CFB-FAG}

As shown in Figure 3, the fatigue lifetime of CFB-FAG shows that the fatigue lifetime of CFB-FAG decreases with the increase of micro strain. The fatigue lifetime of CFB-FAG reached up to 1000000 times when the micro strain is equal to $100 \mu \varepsilon$. Generally speaking, with the increase of CFB-FA content, the fatigue lifetime of CFB-FAG will increase. This results show that both CFB-FA and micro strain can affect the the fatigue lifetime of CFB-FAG. The fatigue lifetime of CFB-FAG appears the mutational point when the CFB-FA content is $25-30 \%$. There exists the optimum content for the fatigue lifetime. It indicates that the CFB-FA content should be controlled at the certain levels $(\leq 25 \%)$.

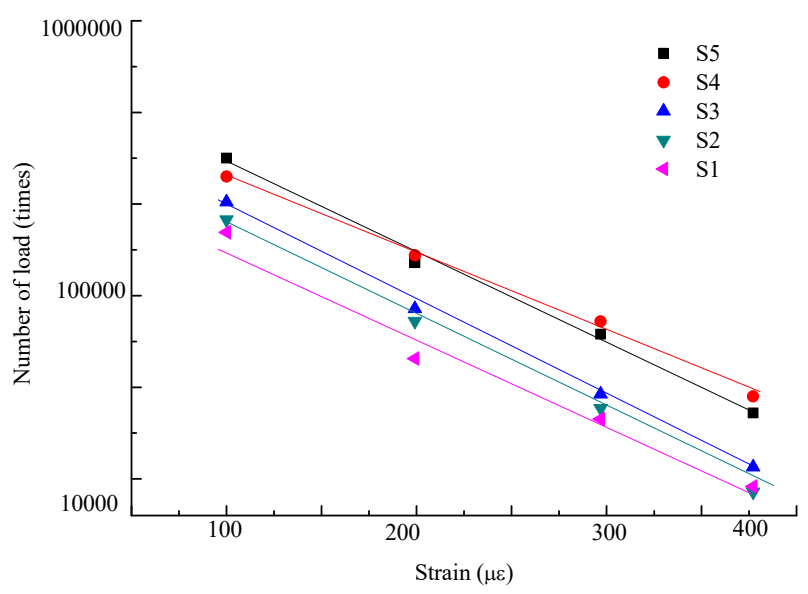

Figure 3. The fatigue lifetime of CFB-FAG.

\subsection{The durability of CFB-FAG}

As shown in Table 3, the durability of geopolymer after acid treatment shows that the durability of S2 is the best and the mass residual is above $88 \%$. The acid resistance of CFB-FAG increased first then decreased with the increase of CFB-FA content. This results show that the CFB-FA can affect siginificantly the acid resistance of CFB-FAG and the optimum content for acid resistance of CFB-FAG is $15 \%$. The different acids have the different effects law on acid resistance of CFB-FAG.
The detailed law is that the acid resistance exists the following las: $\mathrm{H}_{2} \mathrm{SO}_{4}>\mathrm{HCl}>\mathrm{HNO}_{3}$. It indicates that sulfuric acid can affect siginificantly the acid resistance and reduce the durability of CFB-FAG. Further, both hydrochloric acid and nitric acid also affect the acid resistance of CFB-FAG.

Table 3. The mass residual rate of CFB-FAG after acid treatment $(\%)$.

\begin{tabular}{cccc}
\hline Sample & $\mathrm{HCl}$ & $\mathrm{HNO}_{3}$ & $\mathrm{H}_{2} \mathrm{SO}_{4}$ \\
\hline $\mathrm{S} 1$ & 95.0 & 95.8 & 85.0 \\
$\mathrm{~S} 2$ & 98.2 & 99.0 & 88.9 \\
$\mathrm{~S} 3$ & 76.3 & 78.5 & 70.9 \\
$\mathrm{~S} 4$ & 74.6 & 75.2 & 67.0 \\
$\mathrm{~S} 5$ & 73.0 & 74.5 & 60.7 \\
\hline
\end{tabular}

As shown in Table 4, the durability of geopolymer after alkali treatment shows that the mass residal rate of CFB-FAG decreases with the increase of $\mathrm{NaOH}$ concentration. With the increase of $\mathrm{NaOH}$ concentration, the mass redsidual rate of CFB-FAG changed slightly, which indicates that $\mathrm{NaOH}$ concentration will not change significantly the durability of CFB-FAG. The mass residal rate of CFB-FAG after $\mathrm{KOH}$ treatment is less than that of $\mathrm{NaOH}$. The results show that both $\mathrm{NaOH}$ and $\mathrm{KOH}$ decreases the durability of CFB-FAG, while the $\mathrm{KOH}$ effects is more severe than that of $\mathrm{NaOH}$ on the durability. The mass residual rate of S4 is bigger than that of others, which shows that $25 \%$ is the optimum content of CFB-FA for the alkari resistance of CFB-FAG. Furthermore, the different CFB-FA content has the different durability for CFB-FAG.

Table 4. The mass residual rate of CFB-FAG after alkali treatment $(\%)$.

\begin{tabular}{ccccc}
\hline Sample & $\begin{array}{c}0.5 \mathrm{~mol} / \mathrm{L} \\
\mathrm{NaOH}\end{array}$ & $\begin{array}{c}2 \mathrm{~mol} / \mathrm{L} \\
\mathrm{NaOH}\end{array}$ & $\begin{array}{c}6 \mathrm{~mol} / \mathrm{L} \\
\mathrm{NaOH}\end{array}$ & $\begin{array}{c}0.5 \mathrm{~mol} / \mathrm{L} \\
\mathrm{KOH}\end{array}$ \\
\hline S1 & 74.8 & 72.0 & 69.5 & 67.2 \\
$\mathrm{~S} 2$ & 77.0 & 73.0 & 71.2 & 69.8 \\
$\mathrm{~S} 3$ & 80.7 & 75.2 & 74.6 & 73.8 \\
S4 & 99.0 & 98.9 & 98.2 & 84.2 \\
S5 & 96.2 & 95.0 & 89.0 & 85.5 \\
\hline
\end{tabular}

As shown in Figure 4, the CFB-FAG morphology shows that acid or alkari treatment will affect significantly the morphology of CFB-FAG and increase the loose degree of geopolymer. The loose degree of CFB-FAG with acid treatment is more severe than that of alkali treatment. The results show that acid effects is more severe than that of alkari on the durability of CFBFAG. And, there are some C-S-H in the CFB-FAG. With the increase of CFB-FA content, the density of geopolymer increases. The results show that CFB-FA can promote the geopolymer hydration and improve the form of C-S-H hydration products. Also, the acid or alkari will change significantly the morphology and inhibit the hydration of CFB-FAG, especially in alkari treatment. 


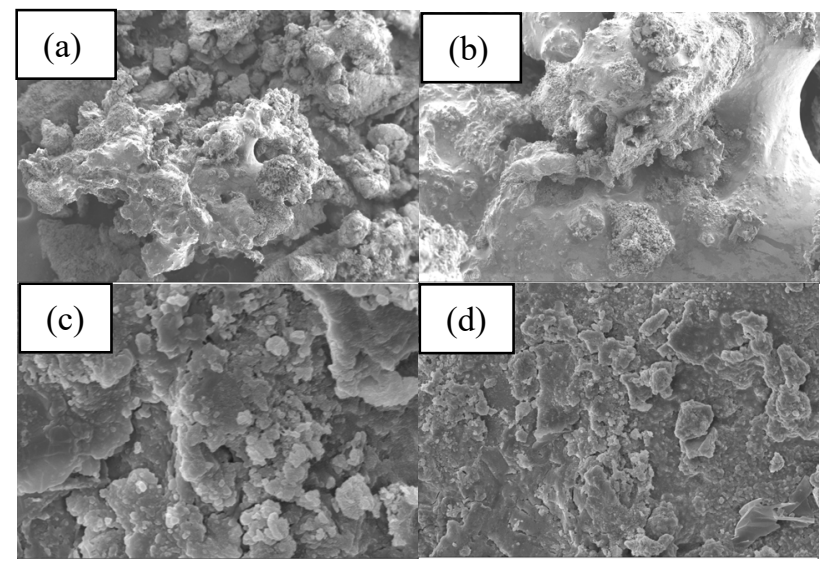

Figure 4. The morphology of CFB-FAG: (a) acid treatment, (b) alkari treatment, (c) $10 \%$ CFB-FA, (d) $15 \%$ CFB-FA.

As shown in Figure 5, the FT-IR results show that the functional groups of CFB-FAG change significantly after acid or alkari treatment. The characteristic peak height and areas of $1025 \mathrm{~cm}^{-1}$ decrease after acid or alkari treatment, which is the asymmetric vibration peak of $\mathrm{Si}-\mathrm{O}-\mathrm{Si}$ or $\mathrm{Al}-\mathrm{O}-\mathrm{Si}$. It indicates that acid or alkari treatment will reduce significantly the hydration product of C-S-H contents and decrease the mechanical properties of CFB-FAG. Further, the durability of CFBFAG will reduce after acid or alkari treatment for CFBFAG. Why dose there exist the phenomenon? The reason is that acid or alkali will change the $\mathrm{pH}$ value during the hydration process and inhibit the hydration reaction. The acid or alkali will also reduce the C-S-H contents of CFB-FAG.

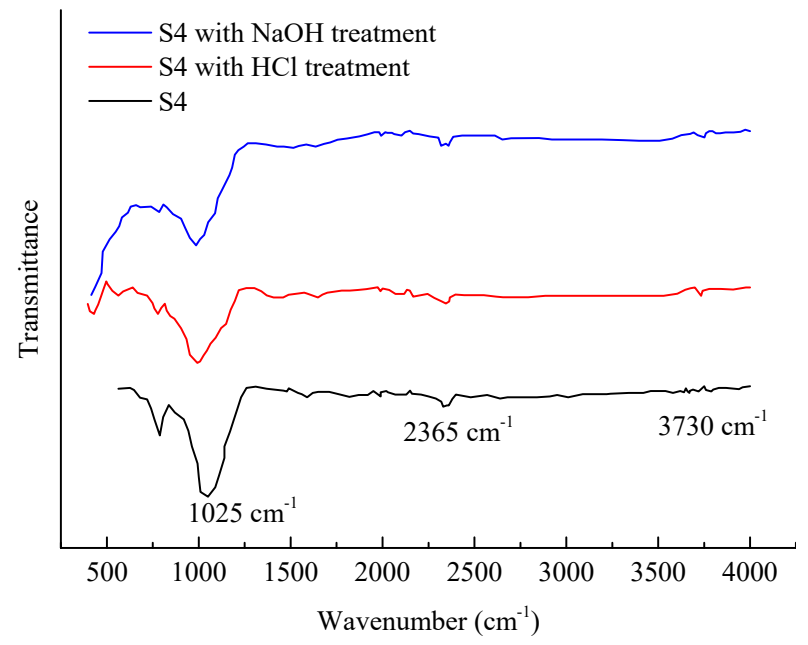

Figure 5. The FT-IR of CFB-FAG.

\section{Conclusions}

The phase composition, mechanical properties, fatigue properites, and durability of CFB-FAG were investigated in this study. Based on the above testing results, the following conclusions can be drawn:

The main components of CFB-FAG are $\mathrm{NaAlSiO}_{3}$, $\mathrm{CaSiO}_{3} \cdot \mathrm{H}_{2} \mathrm{O}$, and amorphous $\mathrm{SiO}_{2}$. Also, CFB-FA do not change significantly the structure of CFB-FAG with the increase of CFB-FA content.
The compressive strength of CFB-FAG is bigger than that of 42.5 P.O cement, and CFB-FA can affect significantly the mechanical properties of CFB-FAG and the optimum content of CFB-FA is $25 \%$. Furthermore, both CFB-FA and micro strain can affect the the fatigue lifetime of CFB-FAG.

Sulfuric acid can affect siginificantly the acid resistance and reduce the durability of CFB-FAG. Further, both hydrochloric acid and nitric acid also affect the acid resistance of CFB-FAG. Both $\mathrm{NaOH}$ and $\mathrm{KOH}$ decreases the durability of CFB-FAG, while the $\mathrm{KOH}$ effects is more severe than that of $\mathrm{NaOH}$ on the durability. The durability of CFB-FAG will reduce the Si-O-Si or Al-O-Si content and affect the durability of CFB-FAG after acid or alkari treatment.

\section{Acknowledgments}

This work was supported by the Special Foundation of Achievements Transformation Guide of Department of Science and Technology of Shanxi Province (No.201804D131034), the Science and Technology Project of Shanxi Transportation Holdings Group Co., LTD (No.18-JKKJ-13, 19-JKKJ-55, and 20-JKKJ-43), and the Innovative Development Plan Projects of Shanxi Transportation Research Institute Group Co., Ltd (No.20-JKCF-10). The authors are grateful and thank all those who helped during this research study.

\section{References}

1. Y. Wang, Y. Alrefaei, J. Dai, Cement Concrete Res, 127,105932 (2020)

2. H. Cho, J. Park, J Mater Cycles Waste, 3, 1-11 (2018)

3. X. Dai, J. Bai, Q. Huang, Fuel, 216, $760-767$ (2018)

4. K. Zhu, F. Matalkah, S. Ramli, J Environ Chem Eng, 6, 113-119 (2018)

5. J. Strigác, N. Števulová, J. Mikušinec, K. Sobolev, Constr Build Mater, 159, 351-360 (2018)

6. J. Pallarés, A. Khadilkar, B. Simcock-Bailey, Fuel, 232, 1-11 (2018) 
7. P. Kaewmee, M. Song, M. Iwanami, H. Tsutsumi, F. Takahashi, J Clean Prod, 272, 122617 (2020)

8. P. He, Y. Zhang, H. Chen, Z. Han, L. Liu, Fuel, 257, 116041 (2019)

9. S. Siddique, H. Kim, J. Jang, Constr Build Maters, 289, 123150 (2021)

10. X. Zhou, J. Shen, Constr Build Mater, 242, 118168 (2020) 